\title{
A VISÃO GARANTISTA ACERCA DAS PROVAS ILIICITAS NO ÂMBITO CRIMINAL
}

http://dx.doi.org/10.21527/2176-6622.2019.51.165-174

Recebido em: 18/9/2018

Aceito em: 4/1/2019

Taciany Amaral de Figueiredo Brambilla

Graduação em Direito pela Universidade Federal do Pará (2010). Especialização em Direito Civil e Direito Processual Civil pela Escola Superior de Advocacia (ESA-SP). Mestranda em Direitos Humanos pela Universidade Federal do Mato Grosso do Sul - linha de pesquisa Direitos fundamentais, democracia e desenvolvimento sustentável. Possui como foco de pesquisa o Estado Garantista desenvolvido por Luigi Ferrajoli. tacianyfigueiredo@hotmail.com

\section{RESUMO}

Este artigo pretende esclarecer como o sistema garantista, idealizado por Luigi Ferrajoli, entende a questão relativa às provas ilícitas na seara criminal. A problemática a ser elucidada é entender se esta modalidade de provas no aspecto penal encontra abrigo na teoria do garantismo, a qual é voltada para o Estado democrático de direito. Para que esta análise fosse efetivada, traçou-se um panorama acerca do projeto garantista, e, posteriormente foi contemplada a temática envolvendo provas ilícitas, na qual se averiguou, ainda, as finalidades da proibição desta prova. Ao fim se estabeleceu um paralelo envolvendo as duas categorias estudadas para se verificar sua compatibilidade. Ressalta-se que os resultados encontrados são centrados na inconformidade desta modalidade probatória com a filosofia política do sistema garantista, a qual delineia todas as matizes garantistas. Utilizou-se a abordagem dedutiva e indutiva a partir da pesquisa bibliográfica, na qual a análise de dados se realizou mediante o estudo de conteúdo para a produção de uma pesquisa com finalidade descritiva. Foi escolhida como marco teórico a obra Direito e Razão: teoria do garantismo penal (2002), de Ferrajoli, para o exame do estado garantista.

Palavras-chave: Sistema garantista. Provas ilícitas. Estado democrático de direito.

THE GUARANTEE VISION ON CRIMINAL ILLEGAL EVIDENCES

\section{ABSTRACT}

This article intends to clarify how the guarantor system conceived by Luigi Ferrajoli understands the question concerning the illegal evidence in the criminal court. The problem to be elucidated is to understand if this modality of evidence in the penal aspect finds shelter in the theory of the garantismo, which is directed to the democratic State of right. For this analysis to be carried out, an overview of the project was drawn up, later the theme involving illicit evidence was considered, in which the purposes of the prohibition of this test were also verified. At the end a parallel was established involving the two categories studied to verify their compatibility. It should be noted that the results found are centered on the nonconformity of this probative modality with the political philosophy of the guarantor system, which delineates all the guarantor shades. The deductive and inductive approach was used based on bibliographical research, in which data analysis was performed through content analysis for the production of a research for descriptive purposes. It was chosen with a theoretical framework of Law and Reason (2002), by Ferrajoli, for the examination of the Guarantor State.

Keywords: Guarantor system. Illegal evidences. Democratic state.

\section{SUMÁRIO}

1 Introdução. 20 sistema garantista. 3 Provas ilícitas. 3.1 Provas ilícitas quanto à violação de direitos fundamentais. 3.2 Provas ilícitas quanto à violação a direitos materiais. 3.3 Provas ilícitas quanto à violação ocorrida em ambiente extraprocessual. 4 Finalidades da vedação à prova proibida. 4.1 Preservação a direitos fundamentais. 4.2 Proteção à integridade processual ou efeito dissuasório. 5 Considerações finais. 6 Referências.

\section{INTRODUÇÃO}

Analisar a questão da prova ilícita é destacar duas das situações mais caras ao Estado de direito. A primeira reside no fato da verificação e respeito aos direitos fundamentais e, a segunda, à qual decorre da primeira, envolve o binômio diametralmente oposto: poder e liberdade. Diante disso, a forma de instituição do sistema penal nos países é alvo de crescentes estudos, tanto no meio jurídico quanto no meio das demais ciências sociais. 
Justificada a necessidade do presente estudo, deve-se expor a via eleita para que ele se concretize. Escolheu-se o tema referente ao modelo garantista, o qual não é apenas uma diretriz para o campo penal, mas demonstra material consistente para orientar os demais ramos jurídicos. Por se trabalhar também com a categoria da prova ilícita penal, o sistema garantista a ser exposto ficará centrado em seus dez axiomas, os quais foram idealizados diretamente para a seara criminal e processual criminal.

O desenvolvimento do tema referente às provas ilícitas é apresentado mediante a contemplação da verdade no mundo processual penal, haja vista que o processo caminha para a formação da sentença de acordo com a elucidação do ilícito verificado. Neste aspecto, será frisada a importância da observância dos direitos fundamentais como limitadores ao poder apurador executado pelo Estado-juiz, bem como serão vislumbrados os aspectos em que o instituto da prova proibida viola a liberdade dos indivíduos. Em seguida, serão tratados os objetivos que fundamentam a sua reprovação.

Por fim, em fase conclusiva, será analisada a possibilidade ou não de compatibilidade do instituto da prova ilícita perante um processo fundamentado nos parâmetros garantistas aqui expostos.

\section{O SISTEMA GARANTISTA}

O garantismo penal é uma construção dogmática elaborada pelo italiano Luigi Ferrajoli, a qual foi materializada na obra Direito e Razão: teoria do garantismo penal, publicada inicialmente em 1989. O cerne do sistema garantista (SG) é a submissão da conduta estatal aos preceitos descritos em texto constitucional, com a finalidade de que sejam reduzidas ao máximo as possibilidades de arbítrio. Esta teoria se amolda melhor ao aspecto criminal, mas Ferrajoli (2002) a decompõe em três sentidos: sistema normativo de direito, teoria crítica do direito e filosofia do direito, os quais retratam sua identificação com o Estado de direito.

Freitas, Mandarino e Rosa (2017, p. 144) resumem, desta forma, o SG em suas mencionadas acepções, confirmando que elas se adequam a um estado que pretenda o status de democrático:

Na primeira concepção, o garantismo é um modelo normativo legítimo do Estado de Direito e implicaria uma limitação estatal punitiva pelos comandos constitucionais. Na segunda concepção, teoria jurídica da validade e da efetividade, a qual se expressa como uma técnica de aproximação entre a existência formal da norma jurídica com a sua efetiva concretização. Na terceira concepção, o garantismo se apresenta como uma filosofia política que requer do direito e do Estado o ônus da justificação externa com base nos bens e interesses dos quais a tutela ou a garantia constituem a finalidade.

A esta forma sintetizada de apresentar os três sentidos do garantismo ferrajoliano, é acrescido que tal sistema é um modelo-limite, ou seja, é um sistema que, de fato, não se verifica no mundo concreto, podendo as ações analisadas aproximarem-se ou se afastarem do ideal arquitetado.

Tem-se que os três aspectos possuem igual importância nesta teoria, mas há que ser destacado o aspecto filosófico. Isto decorre da verificação indubitável que este viés traz em apresentar o Estado como meio e não como fim, ou seja, um instrumento voltado à concretização da melhor tutela da sociedade. Isto representa nada menos que a busca pelo estabelecimento e observância dos próprios direitos humanos.

O SG, além dos três sentidos já expostos, também foi idealizado por Ferrajoli com a argumentação em dez postulados, princípios ou axiomas, os quais o autor entende que são fundamentais para uma maior aproximação à vertente garantista, haja vista que se trabalha com um modelo-limite. Tais axiomas são embasados, assim como o próprio sistema, na corrente jusnaturalista do século 17 ao 18. Desta forma, eles irão expressar a busca por um processo penal mais igualitário às partes, negando antigos privilégios, assim como as abstrações metateóricas que contaminavam a análise da culpa com os preceitos sobrenaturais, os quais apenas se mostravam como mantenedores dos status quo, principalmente econômico e político, de alguns em detrimento de abusividades perpetradas a outras camadas da sociedade.

A importância dos axiomas reside na sua concepção como regras do jogo fundamentais do direito penal, o que, dessa forma, implica necessidade de observância aos participantes sob pena de macular as garantias igualitárias atribuídas a todos os envolvidos. Apesar da citada importância, esses princípios são mais tendendes à adjetivação prescritiva e não descritiva, porém eles descrevem apenas a expectativa da postura a ser adotada pelas partes, ou seja, são implicações deônticas (dever ser). Por se tratar de regra essencial, a conclusão lógica é que eles configuram elementos indisponíveis; logo, a sua privação resulta em poder exarce- 
bado para se decretar punição. Ressalte-se que a maior consequência dos axiomas se refere ao impedimento do uso da arbitrariedade e não a justificar incursões estatais nas esferas de liberdades dos indivíduos. Destaque-se, ainda, que os referidos postulados não são deriváveis entre si, mas sua argumentação foi tracejada de modo a permitir que entre eles haja diálogo, mantendo a coerência do sistema garantista penal.

Ferrajoli (2002), seguindo a tradição latina, apresenta os axiomas no seguinte rol: Nulla poena sine crimine; Nullum crimen sine lege; Nulla lex (poenalis) sine necessitate; Nulla necessitas sine injuria; Nulla injuria sine actione; Nulla actio sine culpa; Nulla culpa sine judicio; Nullum judieium sine accusatione; Nulla accusatio sine probatione; Nulla probatio sine defensione. Nesta lista, deve ser mencionada a alegação do autor ao expor que os princípios de maior complexidade são os relacionados à prova e à defesa, pois trabalham com a conturbada questão da verdade no campo criminal, uma vez que "representa uma utopia que é tão importante perseguir quanto ilusório e perigoso acreditar que seja possível alcançar" (FERRAJOLI, 2002, p. 74).

A condensação desses axiomas é trazida por Carvalho e Carvalho (2002) ao explicarem que uma condenação requer a verificação de um ato ilícito exterior previamente definido como crime, que repercute na esfera jurídica de terceiro, sendo o autor imputável e devendo este ato ser apreciado por juízo imparcial com oportunidade de produção de provas perante acusação pública. Desta forma, tem-se que esses postulados regulam não apenas o processo, mas, por trabalhar com o conceito de crime e suas decomposições necessárias, também geram a parte material.

Passaremos a uma visão panorâmica acerca dos mencionados axiomas perante a sua relevância para verificação em graus do SG.

Nulla poena sine crimine é o primeiro axioma, e nos traz a ideia de retributividade da pena em relação ao fato delituoso, ou seja, a consequência do crime. De acordo com o garantismo, aqui nos deparamos com a pergunta: $O$ que punir? A resposta é que se deve punir um crime, mas esta não é apenas uma condição necessária e não suficiente. Para que seja suficiente devem ser verificadas também condições de procedibilidade, de punibilidade e ausência de eximentes. Isto é indispensável para promover a punição em virtude dos atos praticados que se enquadrem no modelo de crime e, com isso, evitar a condenação em face do que se é, ou seja, do estilo de vida adotado, como ocorreu durante a Inquisição, quando não cristãos eram perseguidos. Este axioma combate a tendência do encarceramento em massa, que se mostra muito mais voltado a uma punição seletiva efetivada contra os mais pobres, como afirma Massimo Pavarini (2002), alegando que a origem deste problema tem nascedouro na crise estatal, em não proporcionar políticas públicas voltadas à inclusão social.

Nullum crimen sine lege, é o postulado que se enquadra no princípio da legalidade. Sua mais forte implicação é proibir a incriminação que não seja determinada por lei. Analisar a legalidade garantista requer sua divisão em legalidade formal e substancial, ou seja, entre a mera legalidade e a conformação da lei aos conteúdos constitucionais (CARVALHO; CARVALHO, 2002). Há, porém, outras decorrências dele que também são importantes, como a proibição da irretroatividade da lei penal, tendo exceção apenas nos casos em que poderá beneficiar o réu; e a necessidade de lei taxativa, para que não se banalize o uso de discricionariedade por parte dos aplicadores da lei.

Baratta e Silvernagl (1985), ao comentarem a obra Ordine pubblico e legislazione eccezionale (FERRAJOLI, 1977), em que Ferrajoli discute políticas públicas que levariam o Estado de direito a se converter em estado policial, diga-se punitivo, ante a violação de garantias, destacam a importância da incorporação da legalidade pelos ordenamentos, uma vez que este postulado, além de fornecer segurança às relações jurídicas, auxilia a diminuição da discricionariedade, o que pode contribuir também para um papel mais eficiente a ser desempenhado pelos serviços públicos. Conforme os autores, a legalidade conflita com expressões indeterminadas, por exemplo, a força maior, sendo tais conceitos utilizados, por vezes, para se evitar fundamentações, gerando, assim, uma decisão arbitrária. Neste contexto, qualquer decisão, desprovida de legítimos motivos, pode, também, justificar ocultamente, ou melhor, encobrir, casos de ineficiência ou desorganização da administração judicial. Desta forma, torna-se mais cômodo, principalmente ao poder criminal, respaldar-se em um conceito vago para se eximir da observância dos direitos. Os autores exemplificam citando que na Itália, na década de 70 do século 20, fazia-se emprego de conceitos abertos nas decisões para legitimar o uso indevido 
da custódia preventiva, quando, em verdade, foram "pensados como respostas contingentes a situações problemáticas ou até mesmo o colapso da 'justiça', essas medidas exasperam os efeitos perversos de uma estrutura disfuncional" (BARATTA; SILVERNAGL, 1985, p. 566).

Nulla lex (poenalis) sine necessitate prega a economia do direito penal. Em outras palavras, este axioma preconiza que o direito criminal deve ser a ultima ratio a ser recorrida quando nenhuma outra forma de intervenção estatal lograr êxito. Ele está relacionado com a pergunta: Como punir? Para responder a esta pergunta é necessário destacar que o próprio fim do Estado Garantista é o cuidado com o indivíduo, ou seja, é a consagração do princípio da dignidade da pessoa humana. Desta forma, somente se torna legítimo efetuar a atuação penal mediante condutas que ataquem bens jurídicos penais e que sua punição não se traduza em penas desumanas ou, ainda, em desequilíbrio com o fato praticado, haja vista que se busca a ação penal como ultima ratio. Trata-se de um aviso, tanto ao Legislativo, em seu momento típico de elaborar leis, principalmente as de execução criminal, proporcionais entre crime e sanção, quanto ao Judiciário, no seu mister de aplicador da lei quando da dosimetria da pena e do cumprimento desta. Exigir do sistema criminal postura diferenciada é convertê-lo em instrumento de controle social, principalmente voltado contra a parte de população hipossuficiente.

Zaffaroni (2007) manifesta apoio a esta forma econômica de se conduzir as tipificações penais. Entende o autor que a inflação de figuras delitivas apenas contribui para o arbítrio seletivo dos órgãos executivos do sistema penal e para o aumento do poder controlador estatal. Neste sentido, temos a confirmação de que o direito penal, nos moldes garantistas, deve se voltar à atuação como ultima ratio.

Nulla necessitas sine injuria. Este axioma possui relação com o princípio da legalidade. A conexão entre ambas reside na imperatividade de se ter uma descrição penal oriunda de uma lei clara quanto à conduta a ser evitada. No que respeita à conduta descrita, há também a observância de que o poder criador a paute quando o bem jurídico estiver em ataque concreto, ou seja, a conduta prescrita deve resultar em perigo de dano, o que se adéqua com o princípio da lesividade ao bem jurídico. Conforme Ferrajoli (2002), a conduta bem-delimitada pelo tipo penal implica proteção maior ao bem a ser defendido, assim como reduz o poder da discricionariedade jurídica nos moldes supraexpostos.

Nulla injuria sine actione. A estrutura deste axioma é fundada no utilitarismo jurídico e na separação entre moral e direito. É vinculado à ideia de que para se afetar a esfera jurídica alheia há a necessidade de a conduta ser manifestada por uma ação no mundo físico que afete terceiros, assim não são considerados os atos internos e que ainda não sejam moralmente reprováveis. Nas próprias palavras do autor, garantista que possui a convicção de que as condutas, para possuírem o status de crime, "devem se concretizar em ações humanas - materiais, físicas ou externas, quer dizer, empiricamente observáveis - passivas de serem descritas, enquanto tais, pela lei penal" (FERRAJOLI, 2002, p. 384) e que não expressem a recriminação em decorrência do caráter do autor, tais como as ideias de pecado.

Nulla actio sine culpa analisa a forma de responsabilização embasada na capacidade de direção do ato pelo agente ao praticar a conduta. Neste postulado temos a valorização da intenção (consciência e vontade) do autor ao executar o fato, ou seja, é verificado o elemento subjetivo, excluindo-se deste campo as implicações acidentais que possam alterar a ação desejada. Desta forma, a culpa é apontada para o elemento subjetivo e não para o resultado (responsabilização objetiva). A culpa no garantismo "atua na avaliação se o homem, socialmente referido, naquelas circunstâncias fáticas, possuía autodeterminação e possibilidade de agir de modo diverso" (CARVALHO; CARVALHO, 2002, p. 48). Sua aplicação resulta na individualização da pena quando ocorre a dosimetria. Neste sentido, a individualização auxilia a medir o grau de reprovabilidade da conduta de acordo com o fato praticado, em que o autor do fato deve possuir condições de autodeterminação.

Nulla culpa sine judicio representa o princípio da jurisdicionalidade. Em suma, cuida-se da entrega da tarefa de analisar os crimes por um órgão que atue pautado pela lei e de forma imparcial, findando-se a fase da vingança privativa, isto é, a apuração da culpa depende de um juízo legitimamente investido. Assim, o uso da jurisdicionalidade se mostra de acordo com a democracia substancial a ser desempenhada pelo Estado, que, ao acolhê-la, também deve incitar a magistratura ao bom desempenho das suas funções, tais como seguir as "regras do jogo" e, principalmente, os valores em jogo (IBANEZ, 1999) para todos, que refletem na própria legitimidade democrática da magistratura, bem como em outros direitos e garantias a serem conferidos aos cidadãos envolvidos no processo. 
Nullum judieium sine accusatione. $\mathrm{O}$ axioma em comento nos reporta ao princípio acusatório. A separação entre o magistrado e as partes é a demonstração elementar de como este axioma deve ser entendido. Ele surge em oposição ao modelo processual inquisitivo, de conotação medieval, que consiste na confusão processual verificada na figura do juiz, uma vez que ele não apenas julga, mas também atua na produção probatória, comprometendo sua imparcialidade e dificultando o desempenho da defesa ao limitar garantias do réu, por exemplo, retirando o caráter de publicidade da colheita probatória. Por sua vez, a construção de um procedimento acusatório requer postura neutra do juiz, no sentido de não se envolver nas questões de produção de prova, mas devendo assegurar a publicidade dos atos praticados. Neste sentido, o juízo torna-se espectador, conferindo igualdade de tratamento às partes. Aury Lopes Junior (2006) aponta como crítica a este axioma e ao princípio da jurisdicionalidade, apresentado anteriormente, a possibilidade de incompatibilização entre a imparcialidade e independência com os poderes instrutórios conferidos ao órgão judicial.

Nulla accusatio sine probatione. Identificado como princípio do ônus acusatório da prova, ele dialoga com o princípio acusatório, posto que na separação entre juiz e acusação o dever de provar os fatos incriminatórios cabe à acusação, pois tem interesse nisso, e não ao juízo, que deve ser comprometido com a busca da verdade e a manutenção das garantias do indivíduo. Com base na explicação, a obtenção probatória que tende à acusação deve ser realizada pela parte interessada perante um juízo regular, aqui devendo ser entendido um juiz imparcial e submetido aos ditames da legalidade, oriunda de um verdadeiro Estado de Direito. Disto extraímos que se deve, antes da prolação do resultado do julgamento, verificar a apresentação pública e adequada, nos moldes já descritos, dos fatos que levam a culpa ao indigitado, para que deles o acusado possa efetuar sua defesa. O contrário levaria à presunção antecipada de não inocência (culpa), o que é entendido como subversão da ordem lógica de um processo que almeja ser garantista.

Analisando este axioma de forma mais teórica, tem-se que ele está atrelado à democracia e às liberdades, não somente pela mera separação entre a atividade julgadora e a acusadora, mas pelas suas consequências, como os poderes da instrução conferidos ao Judiciário. Dotar o órgão julgador de acusatória compromete os ideais de imparcialidade, levando-os a um quadro de paranoia (CORDERO, 1986). Tal afirmação decorre da operação realizada pelo juiz-acusador, a qual resumimos em: "decidir antes e, depois, sair em busca do material probatório suficiente para confirmar a sua versão, isto é, o sistema legitima a possibilidade da crença no imaginário, ao qual toma como verdadeiro" (COUTINHO, 2001, p. 37).

Nulla probatio sine defensione. A expressão da construção dialética e democrática do processo garantista é concretizada neste axioma pelo princípio do contraditório, o qual é condição indisponível para haver o processo penal. Aqui nos deparamos com a principal garantia epistemológica da prova. Segundo Ferrajoli (2002), esta garantia afirma que a prova será adequada quando posta à contraprova, ou seja, refutada, uma vez que afirmar direito à voz a ambas as partes implica paridade de tratamento e de atuação (paridade de armas). Considerar também esta dialeticidade é demonstração de respeito à inocência, até que se prove a culpa em definitivo. Com base neste postulado deve ser mantido ao acusado o direito de exercer sua defesa, as informações de caráter público, por meio técnico, bem como a autodefesa, em todos os desdobramentos da apuração da culpa.

Entendemos que a finalidade dos dez axiomas garantistas, assim como a finalidade do próprio SG, é minimizar os riscos de uma possível atuação desmedida estatal contra direitos dos cidadãos. Mais especificamente em relação aos axiomas, eles irão delinear as formas adequadas para a intervenção estatal a partir do processo penal. Em semelhante ideia, Carvalho e Carvalho (2002, p. 26) expõem

Tais princípios correspondem às "regras do jogo" do direito penal no interior dos Estados democráticos de direito e, dado o fato de sua gradual incorporação constitucional, conformam vínculos formais e materiais de validade jurídica das normas penais e processuais penais.

Trata-se de uma deslegitimação do processo ao se apresentar fundamentos robustos antropocêntricos respaldados no Estado de direito voltado à limitação punitiva estatal (arbítrio) e o próprio erro penal para se obter segurança no processo. Assim, em uma visão reduzida, entende-se que estes modais deônticos conferem legitimidade aos caminhos percorridos ao longo do processo penal, que deverá ser racional e certo. 
Antes de entrar no assunto referente às provas descritas como ilícitas, devem ser realizadas algumas considerações a respeito da importância da matéria probatória para o desenvolvimento do processo penal.

Para Claus Roxin (2003), a prova objetiva leva ao conhecimento do julgador a certeza da ocorrência de algo. Isto faz entender o processo como uma atividade reconstrutiva, a qual será embasada na descrição dos fatos relevantes para o deslinde da causa, trazidos aos autos, o que muitos entendem como a verdade apurada expressa no termo final - a sentença. Neste ponto, tem-se que a verdade pretendida com o processo não é aquela sintetizada pela máxima "os fins justificam os meios". Ao contrário, a verdade, a qual a prova pretende demonstrar, deve ser aquela pautada anteriormente pelas regras que fazem parte do processo, constituindo o que se chama de verdade formal, processual ou aproximativa, como Ferrajoli (2002) a define. Em termos práticos, Aury Lopes Junior (2006, p. 274) estabelece quatro limites que a prova, em um sistema garantista, deve respeitar:

I a tese acusatória deve estar formulada segundo e conforme a norma;

Il a acusação deve estar corroborada pela prova colhida através de técnicas normativamente preestabelecidas; III deve ser sempre uma verdade passível de prova e oposição;

IV a dúvida, falta de acusação ou de provas ritualmente formadas impõem a prevalência da presunção de inocência e atribuição de falsidade formal ou processual às hipóteses acusatórias.

Neste sentido, a prova supera a constatação de verdades absolutas e se torna elemento de conformação entre a atividade desenvolvida pelas partes no processo e o juiz com o rito definidor das garantias de defesa, impedindo o arbítrio estatal e, principalmente, uma condenação infundada. É neste aspecto que se revela a importância da verificação do instituto da prova ilícita, haja vista que a mentalidade inquisitória ainda se faz presente, sendo verificada no Código de Processo Penal brasileiro, o qual apresenta a mescla entre sistema inquisitivo e acusatório.

Entende-se que prova ilícita, seguindo a orientação de Pietro Nuvolone (1966), é gênero da espécie prova vetada (ou proibida), a qual também é gênero da prova ilegítima. De forma mais clara, deve ser entendido que a prova vetada se subdivide em prova ilícita ou prova ilegítima. Esta diferenciação, para o autor, é imprescindível, pois determinará o futuro das citadas provas. A prova ilegítima é obtida em meio a desrespeito às normas processuais, sendo, assim, considerada nula. Por sua vez, a prova ilícita tem sua obtenção contrária às leis materiais, o que a torna inadmissível no processo (GRINOVER, 1982). Em que pese o respeito à tese italiana acerca da classificação das provas vetadas, é salutar apresentar uma outra classificação com diferente abordagem sobre as formas de violações. Por entender que a divisão entre prova ilícita e ilegítima representa um aspecto limitado de entender o assunto, esta pesquisa usará os dois termos como sinônimos, reservando-se a utilizar a diferenciação apenas quando for estritamente necessário.

\subsection{Provas ilícitas quanto à violação de direitos fundamentais}

Segundo Grinover (1982), a produção probatória que não observa os direitos fundamentais é ilícita. A importância de se trabalhar com a violação aos direitos fundamentais, no tocante à prova ilícita, é fruto principalmente da constatação explicitada por Gimeno Sendra, Moreno Catena e Cortés Domínguez (2001), em que o direito penal é o campo de ação estatal em que são concedidos maiores poderes ao Estado, e isto resulta na possibilidade de restrições a direitos fundamentais dos cidadãos.

Diante disso, tem-se que a necessária atenção aos direitos fundamentais concretiza o ideal garantista calcado na maximização dos direitos e na minimização das arbitrariedades, as quais são indispensáveis para a construção do Estado de direito democrático, uma vez que o pretendido Estado implica obediência aos preceitos constitucionais. Neste sentido, quando ocorrer a ruptura da norma contida em texto constitucional com fins de obtenção probatória, se estará diante de uma forma de prova ilícita, a qual é não apenas uma nulidade, mas uma garantia (LORENCES; TORNABENE, 2005).

De acordo com Gloeckner (2010, p. 422), a importância em firmar a defesa a direitos fundamentais e sua consequente invalidade, reflete na busca por um sistema de apuração de culpa mais democrático e menos falho ou abusivo. 
Deve ser frisado que, embora o valor representado pela nulidade/garantia nas situações em que a produção probatória viola os parâmetros constitucionais, o mencionado binômio nulidade/garantia somente surtirá os efeitos desejados caso, de fato, resulte lesão ao preceituado em dispositivo constitucional. Assim, torna-se imperioso haver uma conexão direta entre o estabelecido em Carta Magna e a transgressão praticada.

Ocorre que trabalhar com esta conexão direta, que lese, de maneira grave, a Constituição, gera uma série de problemas que deve ser enfrentada para que se possa decidir pela possível nulidade dos atos. Segundo Ávila (2006), os problemas estão relacionados à discricionariedade, à dificuldade em se comprovar a ligação entre o bem jurídico lesado e ao postulado constitucional, somados à intensidade do dano.

\subsection{Provas ilícitas quanto à violação a direitos materiais}

Esta violação pauta-se na não observância de normas materiais quando do momento da produção probatória. Tem-se aqui a prova ilícita nos moldes em que Nuvolone (1966) a concebeu. Diferente da classificação anterior, que exigia a dupla conformação - previsão constitucional e processual -, esta é satisfeita apenas com a infração a normas de cunho material, categoria desprestigiada na primeira violação (item 2.1). Tal infração legal torna-se um pouco mais complexa de ser observada se comparada a uma violação a direitos processuais, pois o modo em que a prova é levada ao processo é matéria nitidamente formal, fazendo com que o foco esteja muito mais voltado para a verificação dos requisitos processuais em detrimento das circunstâncias da sua produção.

Cabe, anta a dificuldade afirmada mais ao norte, esclarecer como esta violação poderá ocorrer. Para isso, é possível utilizar o seguinte exemplo: imagine que uma determinada forma de prova é admitida por dado ordenamento, desde que respeite a certos critérios estabelecidos processualmente; este mesmo ordenamento, porém, prevê como criminosa uma conduta desempenhada por algum agente público para que a prova fosse produzida, ou seja, a prova é típica e foi realizada mediante a verificação de todos os trâmites formais que a legislação exige, mas sua obtenção mascara a prática de um delito (TÁVORA; ALENCAR, 2016).

Esta situação hipotética concretizou-se, principalmente, em países marcados pela herança de períodos ditatoriais, como o Brasil e o Chile, quando se verificam as alegações de confissões que, aparentemente, respeitaram os requisitos formais, mas que foram forjadas mediante o crime de tortura.

A consequência para a prova que violou diretos materiais é a sua inadmissibilidade nos autos, portanto fica impossibilitada de ser renovada.

\subsection{Provas ilícitas quanto à violação ocorrida em ambiente extraprocessual}

Esta classificação não se relaciona com o tipo de direito desrespeitado, mas, sim com o lugar de "fabricação" da prova (MAGALHÃES GOMES FILHO, 1997). É preferível a palavra fabricação, pois a violação ora analisada está centrada na distinção entre obter e produzir. A obtenção corresponde ao primeiro ato de contato com a prova, que pode ser no processo ou alheio a ele; em suma, é o primeiro acesso que a parte tem à prova, enquanto a produção é o ato subsequente, correspondendo à ação de se incorporar aos autos. Para meIhor interpretação desta categorização é preciso utilizar a redundância, de forma que: a obtenção de uma prova proibida em ambiente extraprocessual causa a inadmissibilidade, logo é uma prova ilícita, não podendo ser renovada; já a produção desse tipo de provas, quando ocorre no curso do processo, é eivada de nulidade, uma vez que não está conforme os procedimentos estipulados.

\section{FINALIDADES DA VEDAÇÃO À PROVA PROIBIDA}

A preocupação em negar a aceitação da prova proibida no processo penal decorre, principalmente, do moderno entendimento referente à busca da verdade no processo. Conforme já explicado, a verdade, hoje almejada para fins processuais, não é admitida de forma irrestrita; ela se apresenta condicionada a certas regras, as quais devem ser respeitadas, e, caso assim não ocorra, restará prejudicado o Estado democrático de direito. Neste mesmo sentido, Rangel (2003, p. 414) elucida as linhas mestras da finalidade desta proibição. Para o autor, "a vedação da prova ilícita é inerente ao Estado democrático de direito que não admite a prova do fato e, consequentemente, punição do indivíduo a qualquer preço, custe o que custar". 
Segundo Magalhães Gomes Filho (1997, p. 6), a finalidade da proibição cumpre um papel político “principalmente na justiça criminal, pois seria absurdo que o Estado, para impor a pena ao autor de um crime, permitisse a prática de métodos criminosos para apurar a verdade sobre o fato".

Já Mendes e Branco (2014, p. 488) trazem a ideia de que a proibição a esta modalidade de prova visa também a criar um efeito dissuasório.

Com base nos dois posicionamentos ora apresentados, serão tecidas considerações a respeito do que se objetiva com a vedação em comento.

\subsection{Preservação a direitos fundamentais}

Conforme Magalhães Gomes Filho (1997), o maior bem a se proteger, em se tratando da exclusão/inadmissão de provas ilícitas, são os direitos fundamentais. Tal resguardo é atribuído à necessidade de fortalecimento do sistema democrático, o qual não mais comporta a desmedida busca por vingança revestida em justiça.

Neste sentido, reconhece-se que a busca pela verdade é limitada a certos parâmetros inafastáveis, e isto resulta no entendimento de que não há nenhum princípio criminal que autorize a apuração da culpa a qualquer preço. A isto também deve ser acrescido que a investigação criminal, e todos os seus atos derivados, não mais pertencem à antiga visão dicotômica entre interesse público e privado, na qual o Estado apresentava supremacia desmedida. Complementando este entendimento, Távora e Alencar (2016) argumentam que a preservação de direitos é o melhor caminho se comparada com a flexibilização, pois esta mitigação, muitas vezes, acoberta a ilegalidade, a qual resulta na insegurança de todos.

A legislação constitucional portuguesa escolheu destacar a sua preocupação com os direitos fundamentais descrevendo a prova ilícita no artigo 32,8 , como nula, sendo assim todas as provas obtidas mediante tortura, coação, ofensa da integridade física ou moral da pessoa, abusiva intromissão na vida privada, no domicílio, na correspondência ou nas telecomunicações. Burgoa (2006), perante o desenvolvimento desta conceituação, afirma que a prova ilícita naquele país deve implicar violações a direitos e garantias fundamentais, ou seja, resultar em lesão à dignidade humana. A legislação processual penal mexicana também foi reformada, em 2011, para melhor se amoldar à proteção das garantias fundamentais (VILLANUEVA, 2017).

No Brasil, a Constituição Federal não prevê, ao tratar da prova proibida, a sua violação a direitos fundamentais; apenas afirma que não serão aceitas as provas obtidas por meios ilícitos. O Código de Processo Penal, reformado em 2008, porém, esclarece que as provas ilícitas são as que violam normas constitucionais ou legais. Desta forma, a partir de 2008 ficou evidente que, no Brasil, tanto direitos fundamentais quanto normas materiais ou formais, fazem parte das violações deste instituto.

Entender que não há méritos em se proteger dos direitos fundamentais, principalmente quando se está diante do Estado-juiz criminal, é admitir o processo como descrito por Kafka (2002): opressor, claustrofóbico, incoerente e, por isso, não é viável contestar ante a certeza da condenação, ainda que injusta. Tal adjetivação poderia ser utilizada para descrever a Inquisição Medieval ou, ainda, o momento ditatorial enfrentado por alguns países da América do Sul, haja vista a supressão injustificada de direitos e garantias.

\subsection{Proteção à integridade processual ou efeito dissuasório}

O efeito dissuasório pretende desestimular as condutas que levam a macular a prova, bem como o processo, haja vista que o seu conteúdo, ainda que desconsiderado, poderá refletir, de forma íntima, na motivação do julgador, por isso também se fala em integridade processual.

Assim, tem- se que o resultado da obtenção de uma prova proibida será a não admissibilidade ou a sua nulidade, em razão da contaminação processual das garantias fundamentais. Este resultado é uma resposta desestimulante à conduta violadora, devendo ser encarado como medida a evidenciar a proteção das fundamentalidades. Logo, a proteção à integridade do processo ou o efeito dissuasório, nada mais representam que um desdobramento à proteção dos direitos fundamentais.

Esta consideração é embasada também no entendimento de que o processo é composto por garantias invioláveis, as quais são necessárias para manter as partes detentoras de sua dignidade e, com isso, servir de desestímulo a possíveis atos estatais que impliquem arbítrio, tais como os praticados em operações policiais, quando agentes públicos "plantam" a evidência, muitas vezes por razões pessoais. É neste sentido de promo- 
ção a atitudes éticas e, consequentemente, o contraestímulo a atitudes que lesem as garantias, que as cortes americanas e alemãs desenvolveram suas argumentações (ÁVILA, 2006). A arguição americana (deterrent efect of policial misconduct) é fundamentada na prevenção dessa conduta indesejada, para que não se tenha de reparar posteriormente. Já o motivo alemão (schtzinstrument der individual-und Grundrechte), que leva à desconsideração desta prova, é o entendimento que o ato de desprezo é um instrumento para se firmar o respeito às garantias. Assim, verifica-se "o processo penal como instrumento de efetivação das garantias constitucionais" (LOPES JUNIOR, 2006, p. 1). Complementa o autor explicando que a instrumentalização processual está, também, a serviço do projeto democrático, com destaque para a liberdade individual, o que contraria o entendimento ultrapassado e antigarantista que expressava a instrumentalidade do processo penal voltada à defesa social, mantendo o Estado como detentor supremo e ilimitado do poder punitivo e protetivo.

\section{CONSIDERAÇÕES FINAIS}

Em verificação ao que foi apresentado mais ao norte, primeiramente será analisado o sistema de garantias de Ferrajoli. Este modelo-limite, percebido nas suas três dimensões (sistema normativo, teoria jurídica e filosofia política) possui toda a sua construção realizada a partir da sua filosofia política, uma vez que esta requer postura estatal como instrumento (meio) e não como fim a pautar suas ações voltadas à sociedade. Neste mesmo sentido, entendeu-se que os dez axiomas materializam a máxima garantista em assegurar o exercício das fundamentalidades elencadas em rol constitucional para balizar a atuação dos órgãos estatais, principalmente quando tais atos possam repercutir na esfera de direitos dos indivíduos. Desta forma, os axiomas são limites impostos ao Estado-juiz, na esfera criminal processual, para controlar ou impedir possíveis abusos.

A temática envolvendo a prova ilícita, seguramente, é reflexo do entendimento dispensado à repercussão da preocupação com a comprovação da verdade quando se analisa o processo. A história já demonstrou que a busca desarrazoada pela verdade pode causar supressão de bens jurídicos valiosos, além de justificar sistemas políticos ditatoriais com a adoção de práticas medievais, como a tortura física. Assim, a busca pela verdade, para o sistema garantista, implica respeito a requisitos mínimos que consigam assegurar, da melhor forma possível, a intrusão estatal na esfera de liberdades do cidadão. Ainda sobre a prova ilícita, com o desenvolvimento de sua conceituação, a qual ultrapassa a classificação referente às infrações a disposições materiais e processuais, e sua consequente inadmissão ou nulidade, foi afirmado que tal classificação é dispensável, por ser verificado que qualquer violação, no tocante à demonstração dos fatos analisados, tende a prejuízos inestimáveis à dignidade da parte. Tal lesão não contém apenas efeito individual, mas torna-se coletiva, por levar a sociedade a um status de insegurança jurídica no tocante aos requisitos em que o Estado aufere a culpa.

Em virtude disso, esta pesquisa, que não pretende esgotar esta temática, porém apenas lançar luzes para a continuação de demais trabalhos de conteúdo semelhante, entende que o sistema garantista, nos moldes que Ferrajoli descreve em Direito e Razão: teoria do garantismo penal (2002), tende a não comportar o instituto da prova ilícita. A exposição para esta negação é embasada na avaliação de que, em se tratando de prova proibida, certamente sua fabricação remonta a uma violação, seja material ou processual; mais certo ainda será o dano causado na esfera de liberdades do prejudicado. Este dano não pode ser admissível, uma vez que, ao lesar a dignidade do indivíduo, fere conjuntamente os ditames constitucionais, os quais são os pilares do Estado Democrático de Direito.

Qualquer justificativa para se constranger direitos e liberdades em prol de um bem maior ou, ainda, da defesa social, é inaceitável se não respeitar com atenção as regras do jogo. Desta forma, não se pode conduzir a conduta processual para confirmar abusos, legitimar vulnerações, e, assim, aniquilar a democracia.

\section{REFERÊNCIAS}

ÁVILA, Thiago André Pierobom de. Provas ilícitas e proporcionalidade: uma análise da colisão entre os princípios da proteção penal eficiente da inadmissibilidade das provas obtidas por meios ilícitos. Brasília, 2006, 295f. Dissertação (Mestrado em Direito, Estado e Constituição) - Universidade de Brasília, Brasília, 2006.

BARATTA, Alessandro; SILVERNAGL, Michael. La Legislación de Emergencia y el Pensamiento Jurídico Garantista. In: Revista Doctrina Penal. Buenos Aires, v. 8, p. 559-580, 1985. Disponível em: https://neopanopticum.wordpress.com/2007/08/24/la-legislacin-de-emergencia-y-el-pensamiento-jurdico-garantista-a-baratta-y-m-silvernagl/. Acesso em: 8 out. 2017. 
BRASIL. Constituição da República Federativa do Brasil. Brasília, DF: Senado Federal, 1988 (atual.).

BRASIL. Código de Processo Penal. Brasília, DF: Senado Federal, 2008 (atual.).

BURGOA, Elena. Prueba Ilicita en el proceso penal portugués. In: RAMIRÉZ, Sergio García; MARISCAL, Olga Islas de González. Panorama internacional sobre justicia penal. Proceso penal y justicia penal internacional. Culturas y sistemas jurídicos comparados. México D. F.: Unam - Universidad Nacional Autónoma de México, 2006.

CARVALHO, Amilton Bueno de; CARVALHO, Salo de. Aplicação da pena e garantismo. 2. ed. Rio de Janeiro: Lúmen Juris, 2002. CORDERO, Franco. Guida alla Procedura Penale. Torino: Utet, 1986.

COUTINHO, Jacinto Nelson de Miranda. Introdução aos princípios gerais do processo penal brasileiro. In: Revista de Estudos Criminais, Porto Alegre, v. 1, n. 1, p. 17 -37, 2001.

FERRAJOLI, Luigi. Direito e razão: teoria do garantismo penal. Trad. Ana Paula Sica et al. São Paulo: Revista dos Tribunais, 2002. FERRAJOLI, Luigi. Ordine pubblico e legislazione eccezionale. La Questione Criminale, Firenze, ano 3, fasc. 3, p. 361-404, 1977. FREITAS, Marisa Helena D’Arbo Alves de; MANDARINO, Renan Posella; ROSA, Larissa. Garantismo penal para quem? O discurso penal liberal frente à sua desconstrução pela criminologia. In: Revista Sequência, Florianópolis, n. 75, p. 129-156, abr. 2017. GIMENO SENDRA, Vicente; MORENO CATENA, Victor; CORTÉS DOMínGUEZ, Valentín. Lecciones de Derecho Procesal Penal. Madrid: Colex, 2001.

GLOECKNER, Ricardo Jacobsen. Uma nova teoria das nulidades: processo penal e instrumentalidade constitucional. Curitiba, 2010, 637f. Tese (Doutorado em Direito do Estado) - Universidade Federal do Paraná, Curitiba, 2010.

GRINOVER, Ada Pellegrini. Liberdades públicas e processo penal. 2. ed. São Paulo: Revista dos Tribunais, 1982.

IBANEZ, Andrés Perfecto. Garantismo y Proceso Penal. In: Revista de la Faculdade de Derecho de la Universidad de Granada, Granada, n. 2, p. 46-65, 1999.

KAFKA, Franz. O processo. Trad. Modesto Carone. São Paulo: Martin Claret, 2002.

LOPES JUNIOR, Aury. Introdução crítica ao processo penal (fundamentos de instrumentalidade constitucional). Rio de Janeiro: Lúmen Juris, 2006.

LORENCES, Valentín; TORNABENE, María Inés. Nulidades en el Proceso Penal. Buenos Aires: Editorial Universidad, 2005.

MAGALHÃES GOMES FILHO, Antônio. Direito à prova no processo penal. São Paulo: RT, 1997.

MENDES, Gilmar Ferreira; BRANCO, Paulo Gustavo Gonet. Curso de Direito Constitucional. São Paulo: Saraiva, 2014.

NUVOLONE, Pietro. Le prove vietate nel processo penale nei paesi di diritto latino. Rivista di diritto processuale, Padova, v. XXI (II Série), p. 35-78, 1966.

PAVARINI, Massimo. Control y Dominación: teorías criminológicas burguesas y proyecto hegemónico. Trad. Ignácio Munagorri. Buenos Aires: Siglo XXI Editores Argentina, 2002.

PORTUGAL. Constituição da República Portuguesa. 1974 (atual.) Disponível em: https://www.parlamento.pt/Legislacao/Paginas/ConstituicaoRepublicaPortuguesa.aspx. Acesso em: 8 maio 2018.

RANGEL, Paulo. Direito Processual Penal. Rio de Janeiro: Lúmen Juris, 2003.

ROXIN, Claus. Derecho Processual Penal. Buenos Aires: Editores Del Puerto, 2003.

TÁVORA, Nestor; ALENCAR, Rosmar Rodrigues. Curso de Direito Processual Penal. 11. ed. rev. atual. e ampl. Salvador: Ed. Juspodivm, 2016.

VILLANUEVA, Raúl Plascencia. La Prueba Ilícita. In: RAMIRÉZ, Sergio García; MARISCAL, Olga Islas de González. Evolución del sistema penal em México. Tres cuartos de siglo. Proceso penal y justicia penal internacional. Culturas y sistemas jurídicos comparados. México D.F.: Unam - Universidad Nacional Autónoma de México, 2017.

ZAFFARONI, Eugenio Raul. O inimigo no direito penal. Rio de Janeiro: Revan, 2007. 